\title{
O RELACIONAMENTO COLABORATIVO NA CADEIA DE SUPRIMENTOS DO MCDONALD'S
}

\section{THE COLLABORATIVE RELANTIONSHIP OF THE SUPLLY CHAIN OF MCDONALD'S}

\author{
Mauro Vivaldini ${ }^{1}$; Fernando Bernardi de Souza ${ }^{2}$; Silvio R. I. Pires ${ }^{3}$ \\ ${ }^{1}$ Metodista University of Piracicaba - UNIMEP - S. Barbara - Brasil mvivaldini@mbbrasil.com.br \\ ${ }^{2}$ São Paulo State University - UNESP - Bauru - Brasil fbernardi@feb.unesp.br \\ ${ }^{3}$ Metodista University of Piracicaba - UNIMEP - S. Barbara - Brasil sripires@unimep.br
}

\begin{abstract}
Resumo
Através da análise da cadeia de suprimentos do McDonald's, o estudo apresenta como o relacionamento colaborativo pode ser entendido na gestão do sistema e no processo de abastecimento dos restaurantes. O embasamento teórico explora o relacionamento na gestão da cadeia de suprimentos e o processo colaborativo como mecanismo de coordenação dos agentes da cadeia. Sendo o McDonald's um caso representativo e de relativo interesse acadêmico, principalmente na sua gestão de suprimentos, acredita-se que o estudo contribua para o entendimento do tema, além de esclarecer fatores que favorecem e beneficiam as empresas na utilização do conceito. Considerando a discussão sobre relacionamento colaborativo na cadeia de suprimentos um tema ainda em evolução, este caso ajuda a dar embasamento a idéias e estudos futuros a respeito do assunto.
\end{abstract}

Palavras Chave: Cadeia de Suprimentos; Relacionamento Colaborativo.

\section{Introdução}

Uma característica que muito contribui para os resultados das organizações é o bom gerenciamento da cadeia de suprimentos. Neste processo, em que as empresas têm possibilidade de trabalhar com fornecedores, clientes e mercados de forma integrada, a necessidade de coordenação e cooperação entre os diversos agentes envolvidos é fundamental.

Muito se discute sobre a tendência de que a competição por mercados será definida não por empresas individuais, mas sim pela gestão da cadeia de suprimentos. Conceitualmente, esta abordagem tem sido bem difundida, trabalhada e ilustrada por diversos casos e exemplos. Em uma era de concorrência de redes, as recompensas irão para as organizações que puderem melhor estruturar, coordenar e gerenciar os relacionamentos com seus parceiros em uma rede comprometida com relacionamentos melhores, mais estreitos e mais ágeis com seus clientes finais (CHRISTOPHER, et al 2001; HARRISON, et al, 2002; COX, 2004). 
Ao longo dos últimos anos, várias abordagens em logística e suprimentos têm sido utilizadas para dar competitividade às empresas, de forma a recuperar a rentabilidade pressionada pelo novo ambiente de negócios, bem como responder mais rapidamente às necessidades dos consumidores (LAMBERT et al., 1996 e 2000, SIMATUPANG et at., 2002; JOHANNESSEN et al., 2002; BRONZO, 2004). Atualmente, o gerenciamento da cadeia de suprimentos - numa postura colaborativa e em sintonia com a visão mais moderna e sistêmica da logística - é o campo onde a maioria das empresas vê possibilidades de melhoria na performance e/ou de agregar valor aos seus produtos e serviços (ZHAO et al., 2003 e BARRATT, 2004).

Muitos estudos têm sido feitos e publicados sobre o tema gerenciamento da cadeia de suprimentos, aumentando a compreensão do assunto e avançando o conhecimento. Dentro desta perspectiva, parece oportuno descrever e analisar a cadeia de abastecimento de uma empresa de atuação global, reconhecida em todo o planeta como um ícone do capitalismo e da cultura americana, que tem na gestão de suprimentos um dos seus diferenciais competitivos, servindo de modelo para inúmeras outras empresas: a rede de restaurantes fast food McDonald's. Segundo pesquisa da FGV (2004), o faturamento bruto da empresa no Brasil em 2003 foi de R\$ 1,7 bilhões, com 500 milhões de consumidores/ano em cerca de 1200 pontos de venda, contando com 36 mil funcionários e 30 mil empregos indiretos.

Buscando uma descrição de forma mais sistêmica do assunto, o presente estudo baseia-se nas abordagens propostas por Bowersox et al (2003), Barratt (2004), Cox (2004) e Beckett (2005) sobre relacionamento colaborativo na gestão da cadeia de suprimentos como um processo de integração, sobre a complexidade que é administrar os interesses individuais das empresas e sobre a interdependência organizacional e tecnológica existente entre elas.

Dado o porte da empresa McDonald's e a sua visibilidade no mundo corporativo, podendo ser considerada, em alguns aspectos, como um exemplo de gestão a ser seguido, supõe-se que haja grande interesse no estudo e no conhecimento de suas atividades, notadamente na forma como é administrada a sua cadeia de suprimentos, apontada por muitos como um dos fatores que mais contribuem para o sucesso de suas operações.

Além desse resultado, como contribuição deste artigo está a utilização de uma abordagem ainda alternativa para descrever uma situação encontrada na prática. Com isso, além do emprego de um instrumento novo, colaborando para um entendimento mais amplo da situação, também será possível verificar os benefícios decorrentes da sua utilização.

Metodologicamente, o objetivo do presente estudo é descrever e analisar uma cadeia de abastecimento reconhecida como referência em termos de eficácia e de eficiência, segundo uma visão colaborativa entre seus agentes. 
A descrição da cadeia de suprimentos do sistema McDonald's no Brasil é feito, então, na forma de um estudo de caso em que o pesquisador tem a oportunidade de observar e analisar um fenômeno muitas vezes inacessível à investigação científica, principalmente ao considerar a possibilidade de utilização de informações internas à empresa. O motivo da escolha do McDonald's foi a posição da empresa como um símbolo do modo de produção e da cultura do capitalismo do final do Século XX e pelo fato dessa empresa contar com sua cadeia de suprimentos como uma fonte de vantagem competitiva. A existência de uma cultura muito facilmente identificável na empresa, por outro lado, favorece a análise do processo colaborativo, organizacional e tecnológico.

Os dados tanto do próprio McDonald's, como dos seus parceiros, foram obtidos junto aos executivos dessas empresas, por meio de entrevistas semi-estruturadas e visitas às suas instalações.

\section{Desenvolvimento Teórico}

Este trabalho está fundamentado em uma revisão bibliográfica com foco em dois aspectos principais: a colaboração e o relacionamento na cadeia de suprimentos.

\subsection{Compreendendo a Colaboração na Cadeia de Suprimentos}

Lambert et al. (1996) e Cooper et al. (1997), em estudos sobre a gestão da cadeia de suprimentos, parcerias e logística já discutiam a importância das organizações estabelecerem relacionamentos colaborativos na intenção de manter liderança e crescimento de mercado. $\mathrm{O}$ conceito ganhou uma maior dimensão ao longo dos anos, tanto que Lambert (2000), anos depois, mencionava em seus estudos a importância do reconhecimento dos clientes aos supridores e operadores logísticos na performance dos negócios.

Nesta linha, a empresa foco (cliente de supridores e operadores logísticos) que tem o domínio da cadeia, deve estabelecer e definir as relações, conceitos e cultura comercial que balizará sua gestão na cadeia. Aliado a este pensamento, Peck (2000) chama de estratégia coletiva a intenção de melhorar a habilidade de cada agente em prever e entender as ações dos outros membros da cadeia. Considerando ser este processo um arranjo inter-organizacional complexo, é importante que a empresa foco exerça a governança da rede, buscando estimular a eficiência coletiva (TEIXEIRA et al, 2002).

Simatupang et al (2002) afirmam que habitualmente os membros da cadeia trabalham como empresas individuais com perspectiva local e conduta oportunista. Porém, este comportamento vai contra a rentabilidade da cadeia de suprimentos. Estabelecer a cooperação da cadeia ajuda a ajustar a demanda e melhorar a rentabilidade. Neste sentido, os autores definem a cadeia de suprimentos 
colaborativa como duas ou mais empresas independentes trabalhando conjuntamente para planejar e executar operações de suprimentos com maior sucesso do que atuando isoladamente. Ou seja, a colaboração é baseada em objetivos mútuos.

Entende-se que a gestão da cadeia de suprimentos continuará a influenciar as empresas através da busca de ações diferenciadas, processos de terceirização, compressão dos elos, e colaboração dos parceiros. Isto será utilizado para reestruturar as redes de suprimentos e melhorar a coordenação (KOPCZAK et al., 2003).

A integração da cadeia de suprimentos para a grande maioria das empresas é apenas uma promessa, apesar dos esforços das organizações, seus clientes e supridores (BARRATT, 2003). Isto tende a ocorrer porque a cultura desenvolvida na cadeia não privilegia ações colaborativas, nem trabalha a importância do desenvolvimento do negócio para todos os agentes, tornando a visão de cada empresa limitada e individualizada.

O relacionamento com enfoque na gestão colaborativa surgiu com o avanço de práticas de integração e melhorias nos processos de comunicação e informação, como o ECR (Efficient Consumer Response), VMI (Vendor Managed Inventory), CR (Continuous Replenishment), e CPFR (Colaborative Planning, Forecasting, and Replenisment). O CPFR, por sua vez, tem tido grande influência no desenvolvimento e divulgação da importância de atitudes colaborativas.

Muitos estudos em cadeia de suprimentos adotam o conceito de "cadeia colaborativa ou colaboração na cadeia", independente dos conceitos e práticas seguidas no CPFR. Isto ocorre por considerarem o processo colaborativo como o desenvolvimento de um trabalho mais integrado entre os agentes, com maior troca de informações, divulgação de ações e processos relativos à cadeia, bem como a administração da performance do negócio (BARRATT, 2003 e SIMATUPANG et al., 2004).

Para Sahay (2003), a visão do processo colaborativo é ter os supridores, produtores, distribuidores e clientes alinhados em prol de um relacionamento cooperativo, para benefícios da cadeia e de cada agente. Ou seja, adotar uma perspectiva externa, em que a decisão das empresas deve considerar não somente sua performance individual, mas de toda a cadeia.

Este compromisso no relacionamento exige dos agentes da cadeia um planejamento colaborativo que consiste no gerenciamento da demanda. Isto ocorre com uma gestão de informação e dados em tempo real entre os membros da cadeia (BARRATT, 2003). A compreensão desta prática não é simples. Tanto no aspecto global da cadeia quanto individual, os conflitos e dificuldades são pertinentes a um processo colaborativo e a coordenação das ações através de um comitê liderado pela empresa foco - governante - pode contribuir para o sucesso do relacionamento na cadeia. 
Para obter benefícios do planejamento colaborativo e integração da cadeia de suprimentos, as organizações devem assegurar integração interna com marketing e produção. A integração interna e externa com os parceiros depende da troca de informação e do alinhamento do processo (BARRAT, 2004).

Corsten et al (2005), numa pesquisa sobre colaboração dos supridores, apontam que a colaboração tende a ser mais favorável para quem compra, ou seja, para a empresa que tem a governança da cadeia. Também, os autores não deixam de ressaltar a validade da colaboração na cadeia, mas destacam a complexidade que é implementá-la, citando que este processo precisa estar inserido num mecanismo de governança que inclui um relacionamento controlado, monitorando a dependência e construindo a verdade.

\subsection{O Relacionamento na cadeia de suprimentos}

Para Min et al. (2005), o entendimento entre os parceiros exige muitas horas para se explorar e compreender o que seria benefícios mútuos, exigindo muitas sessões e discussões para ajustes entre as organizações. Os autores, que descrevem no quadro 1 a seguir as principais atividades colaborativas, também reforçam o aspecto de que as informações devem ter um caminho que ajude as operações, além de serem respeitadas por todos como confidenciais.

Quadro 1 - Principais atividades colaborativas

\begin{tabular}{|ll|}
\hline Compartilhando Informação & Prevendo \\
& Demanda do Cliente \\
& Necessidade de materiais \\
& Plano de marketing \\
& Capacidade de Produção e Programação \\
Planejamento conjunto & Objetivos de performance e vendas \\
& Orçamentos \\
& Priorizando metas e objetivos \\
& Desenvolvendo produtos \\
Resolvendo problemas & Problemas logísticos (embarques, rotas, \\
& tamanho de pallet, embalagens, etc.) \\
& Suporte de marketing (material de mkt, entrega, \\
display de loja, etc.) & Controle de qualidade \\
Análise de custo-benefício (custo de estoque, \\
lead-time, serviço ao cliente, etc.) \\
Baseline e revisão da performance \\
KPIs (serviço ao cliente, redução de custo, \\
produtividade, etc.) \\
Determinando recompensas e ações corretivas \\
Recursos e capacidades \\
Habilidades e conhecimentos \\
Especialização \\
Alavancagem
\end{tabular}

Fonte: Min et al., 2005 
Se a relação entre as empresas da cadeia ocorre segundo as atividades sugeridas no quadro 1, o conceito de trabalhar junto para ganhos mútuos fica evidente se o espírito colaborativo for institucionalizado e ganhar credibilidade (BOWERSOX et al., 2003). No entanto, o fato desta idéia não ser tão forte na prática tem sido motivo de diversos questionamentos na literatura a respeito do processo de colaboração na cadeia de suprimentos.

Cox (2004) é um dos autores que tem questionado parte do idealismo inerente aos conceitos da relação na cadeia de suprimentos, em que muitos autores defendem a relação ganha-ganha. Não que isso não possa ocorrer, nem que o relacionamento colaborativo seja ficção, mas a idéia é a de que se isto se aplica a um mercado ou seguimento ou empresa, não necessariamente poderá funcionar em outro. Como também, o ganhar de um pode não se refletir na mesma proporção em outro fornecedor ou camada da cadeia e, nem mesmo por isso, a relação pode ser quebrada. Neste caso, segundo Simatupang (2004), isto ocorre provavelmente porque os parceiros da cadeia tendem a não ter dimensão nem visão da performance dos demais na cadeia, nem mesmo visão total dos resultados buscados pela empresa foco da cadeia .

Ainda para Cox (2004), muitas companhias somente são capazes de administrar a relação na cadeia de suprimentos na primeira camada (first tier). Isto significa que, apesar do conceito de cadeia de suprimentos contribuir para os negócios, seu alcance ainda tem muitas limitações. Para vencer estas restrições, as companhias precisam ter recursos internos e capacidade operacional para praticar e ganhar esta amplitude.

Bowersox et al. (2003) apontam que a terceirização funcional, como atividades que vão da manufatura a serviços logísticos como transporte e armazenagem, é gerencialmente determinada e governada por princípios de comando e controle. Numa visão de contribuição e evolução deste tipo de relação, eles estabelecem uma abordagem sobre o relacionamento entre as empresas em que estas integram seus esforços e recursos na busca de um novo, mas eficiente e efetivo ou relevante modelo de negócio, gerenciado por um apropriado mecanismo de governança. Nesta relação, as empresas procuram eliminar processos duplicados e não produtivos na busca de maior produtividade, estabelecendo objetivos mútuos. Esta relação requer uma básica modificação no processo de negócio, que aproxima as empresas no longo prazo e numa estrutura operacional conjunta. Neste modelo o autor entende como competências e capacidades necessárias às empresas:

Processo de Liderança;

Planejamento e Controle do Processo;

Processo de Operação Integrada.

Numa linha semelhante, porém com foco na logística, Closs et al. (2005) utilizam o termo flexível para demonstrar a importância de se encontrar habilidades organizacionais que atendam aos requisitos do cliente, comprovando que a flexibilidade logística tem efeito significante e direto na 
performance. Esta, por sua vez, segundo Cox (2004) só será relevante se as empresas envolvidas na relação entender que o alinhamento interno é tão importante quanto o alinhamento externo.

Portanto, nesta extensão da relação entre os elementos da cadeia de suprimentos, a visão do valor das atividades não pode ficar restrita somente aos supridores da primeira camada, mas também, aos demais da segunda ou terceira, pois eles também agregam valor ao processo (DORAN, 2003).

Como afirmam Rungtusanathan et al. (2003), a integração entre uma empresa e seus supridores e clientes deve continuamente prover oportunidades de melhorias que facilitem as operações internas. Considerando uma relação cliente - provedor logístico, a operação existente entre um (Prestador de Serviços Logísticos) PSL e seu supridor pode ser como uma operação interna do PSL, que tem o desafio de administrar seus supridores com foco e performance condizentes com o negócio de seu cliente.

\section{A História da Cadeia de Suprimentos McDonald's}

O texto que segue, com enfoque dos autores na cadeia de suprimentos, está baseado no livro de Love (1996), que descreve a história do McDonal's.

\subsection{O Sistema McDonald's}

A história da corporação McDonald's, maior empresa de food service do mundo, está intimamente ligada à história de seu fundador Ray Kroc, que foi a primeira pessoa a comercializar em massa os produtos e a marca McDonald's. Kroc recebeu a fama de criador do restaurante de self service e atendimento rápido, apesar de não tê-lo inventado. O crédito da invenção pertence aos irmãos McDonald, Richard e Maurice.

Por volta de 1937, os californianos já começavam a sentir uma extraordinária dependência do automóvel, o que fez com que alguns comerciantes que antes possuíam restaurantes convencionais introduzissem um novo ramo de negócios, isto é, restaurantes para clientes motorizados, chamados de restaurantes drive in. Pátios de estacionamento grandes e de fácil acesso, aliados a um serviço de garçonetes contratadas para servir aos clientes em seus automóveis, eram a essência do novo negócio.

Os irmãos McDonald abriram em 1937 seu primeiro restaurante drive-in, a leste de Pasadena. Era um restaurante pequeno, mas que levou os irmãos McDonald a abrir um outro restaurante em San Bernardino, cerca de 80 quilômetros a leste de Los Angeles, uma cidade que estava se tornando uma próspera moradia da classe trabalhadora. Em meados dos anos 40, o 
restaurante era o principal ponto de encontro dos adolescentes da cidade, e 25 garçonetes serviam cerca de 125 automóveis que lotavam o pátio de estacionamento nos finais de semana.

A partir de 1948, os irmãos McDonald começaram a sentir a pressão da concorrência, além de considerarem que o sistema de operação do restaurante drive in estava limitado economicamente. Decidiram, então, que deveriam mudar totalmente seu modo de atuação, baseados na descoberta de que os hambúrgueres representavam $80 \%$ do negócio. A descoberta foi o princípio de uma revolução no food service. As mudanças ocorridas foram:

- Foco do negócio em velocidade, preços baixos e volumes elevados.

- Cardápio reduzido de 25 itens para 9 itens (principalmente hambúrgueres).

- Eliminação das garçonetes, e conseqüente introdução do sistema self service.

- Introdução de conceitos ligados à linha de produção nos restaurantes, como reconfiguração e layout da cozinha para gerar rapidez e grandes volumes de produção, rígidos procedimentos operacionais para eliminar a influência do elemento humano, pratos pré-temperados (redução da variedade de produtos), e produção para estoque (make to stock).

- Substituição de louças e talheres por sacos de papel, papel de embrulho, invólucros e copos de papel.

- Novo segmento de mercado: famílias, com apelo especial para crianças.

- Desenvolvimento de equipamentos feitos sob medida para as novas necessidades das cozinhas

Os irmãos McDonald tinham claramente desenvolvido um sistema muito diferente, assim como as mesmas tendências que substituíam os "armazéns da esquina” por supermercados.

O sucesso do restaurante dos irmãos McDonald, em San Bernardino, provocou o interesse de terceiros em abrir franquias do restaurante. O sistema de franquias iniciado pelos dois irmãos foi um fracasso, principalmente pela falta de energia e habilidades organizacionais dos inventores do novo tipo de restaurante, bem como pela visão de lucro imediato e falta de comprometimento com os franqueados. Em 1954, Ray Kroc, um vendedor de equipamentos para a indústria de food service, na época com 52 anos, reconheceu a oportunidade de expandir a rede de restaurantes em escala nacional. Kroc presenciou o sucesso do restaurante em San Bernardino, e, dado o baixo custo de construção do mesmo, percebeu que ele preenchia um vazio no food service, e era perfeito para um sistema de franchising. Assim, depois de uma breve negociação com os irmãos McDonald, Kroc fundou em 2 de março de 1955 uma nova firma de franchising, a McDonald's System. 


\subsection{Disseminação dos princípios colaborativos de Ray Kroc}

Kroc introduziu uma nova abordagem para o sistema de franquias, cujo objetivo era o sucesso imediato dos franqueados, para que no longo prazo o sistema como um todo se beneficiasse . Sua idéia era prestar aos franqueados serviços suficientes para que fossem bem sucedidos. Essa filosofia era similar à filosofia que adotou quando vendia suprimentos para o setor de food service, em que o sucesso se baseava em descobrir meios de fazer seus clientes bem-sucedidos com o seu produto.

Ele acreditava que estava no negócio para servir seus franqueados e desenvolver sua lealdade, e que os mesmos eram seus clientes e que, se falhassem, ele falharia também. Assim, o relacionamento entre corporação e franqueados foi sendo pautado sempre em termos de lealdade, confiança e comprometimento, induzindo um comportamento colaborativo e harmonioso. O mesmo relacionamento aberto se esperava dos fornecedores, e exigia-se que os custos e preços dos mesmos fossem inteiramente abertos para que os franqueados soubessem que a corporação não estava se beneficiando de quaisquer parcelas.

Assim, Ray Kroc conseguiu unir os três elementos do sistema McDonald's - franqueados, corporação e fornecedores - numa só "família", com um propósito comum. Os participantes do sistema tinham incentivos comuns e um padrão comum de qualidade, serviço e asseio, além de existir um controle mútuo entre todos os elementos. $\quad \mathrm{O}$ sistema deveria ser controlado por decisões e políticas consideradas pelo bem comum, sendo bem comum definido como a interação entre todos os participantes.

\subsection{A Cadeia de Suprimentos}

As inovações promovidas pelos restaurantes McDonald's, a partir da década de 50, trouxeram consigo a necessidade de desenvolvimento de novos equipamentos e produtos adequados a uma nova realidade. A princípio, os grandes fornecedores da indústria de food service fizeram tentativas para abastecer os restaurantes, porém não foram capazes de atender as exigências mais severas demandadas pela maioria dos restaurantes da época, ou não tinham interesse em fazer nada diferente do que vendiam aos demais. Para esses grandes fornecedores, maximizar a capacidade produtiva em uso era bem mais seguro do que construir uma nova capacidade e se arriscar em negócios futuros do McDonald's.

Assim, os fornecedores selecionados para atender aos restaurantes eram pequenos, e estavam também iniciando seus negócios. Estavam dispostos a dividir os riscos e customizar suas 
operações produtivas e áreas de serviços, de forma a atender todas as inovações de produtos e processos requeridas pelo McDonald's.

Em meados da década de 60, o crescimento da cadeia de restaurantes, aliado à crescente competitividade de seus concorrentes, fez com que a cadeia de suprimentos assumisse papel de destaque nas estratégias do McDonald's: era necessário a expansão em escala nacional, porém a fonte de fornecimento era composta de pequenos produtores, e a utilização de grandes fornecedores seria a escolha mais lógica. Contudo, o McDonald's criou, ao invés de trabalhar com um grupo desorganizado de fornecedores independentes, um sistema integrado, eficiente e inovador de abastecimento.

É interessante destacar que a estratégia adotada na cadeia de suprimentos se baseou na transferência de parte da mão-de-obra envolvida no preparo de alimentos nas lojas de volta às fábricas que os forneciam. Os produtos eram fabricados de modo mais padronizado, fazendo com que a preparação de alimentos na loja se tornasse quase infalível. É interessante notar a estratégia de especulação na cadeia de suprimentos, antecipando a transformação dos produtos, ao invés de postponement, estratégia bastante utilizada nas cadeias de suprimento atualmente.

A produção concentrava-se em imensas fábricas dedicadas exclusivamente ao McDonald's, o número de fornecedores era bastante reduzido e as companhias responsáveis pela distribuição eram poucas.

O McDonald's desenvolveu em seus fornecedores um compromisso fortíssimo de atendimento ao sistema, fazendo-os parte do sistema McDonald's. Uma vez que esses fornecedores eram pequenos e cresceram junto com a rede McDonald's, compartilhando missões, objetivos, crenças e valores, o comportamento sempre se deu de forma colaborativa e cooperativa. A própria cultura organizacional das empresas pertencentes ao sistema McDonald's reflete a cultura do McDonald's. Os fornecedores tornam-se tão dedicados à manutenção e melhoria da qualidade do sistema como se fossem propriedade do McDonald's.

A extensão da cultura McDonald's à cadeia de suprimentos pode ser entendida visualizandose a rotina diária dos funcionários dos fornecedores; por exemplo, nos centros de distribuição da Martin-Brower no Brasil (Prestador de Serviços Logísticos da rede no Brasil), os funcionários vêem mais os símbolos do McDonald's do que os da própria Martin-Brower. O símbolo tradicional do McDonald's está espalhado por toda a companhia, desde os "broches", caixas movimentadas no armazém, cartazes de promoções nos corredores principais, logotipos nos caminhões, até brindes promocionais distribuídos nos restaurantes em cima das mesas dos gerentes, e, o mais intrigante, alguns pensamentos da filosofia de Ray Kroc estão presentes no vídeo institucional da empresa. Embora, atualmente a Martin-Brower tenha outros clientes, seu propósito principal, até então, é atender o sistema McDonald's, como citado por seus executivos. 
A base do relacionamento com os fornecedores foi pautada da mesma forma que com os franqueados, tendo em vista sempre a lealdade, confiança e comprometimento. A cadeia não se acha presa por nenhum requisito legal a qualquer um de seus fornecedores. Seus contratos são firmados apenas com um aperto de mão, nunca por escrito, mesmo com companhias cujos negócios dependem totalmente do McDonald's. A negociação é baseada em planilhas de custos abertas e na instalação de parcerias na área operacional, como foi a construção do condomínio Food Town um complexo operacional que reúne fábricas e o operador logístico num mesmo local no intuito de integrar ainda mais o sistema de atendimento, reduzindo custos de transferências de produtos e melhorando a performance de abastecimento. Isto ilustra a transparência e cooperação entre os diversos elos da cadeia de abastecimento.

Os principais fornecedores do sistema McDonald's no Brasil são: Martin-Brower (Prestador de Serviços Logísticos), Junior e Unilever (molhos), OSI (carne), McCain (batata), Schreiber (queijos), Fresh Start (pão), Brasilgráfica (embalagens), Dixie (copos), Polenghi e Batavia (sorvete) e Refricon (hortifrutigranjeiros).

\section{Análise do Caso}

Este tópico apresenta o estudo de caso anteriormente proposto, focalizando a visão e as formas de gestão da cadeia McDonald's.

\subsection{Visão da Cadeia}

Através de um resumo da descrição da cadeia de suprimentos do McDonald's citada no relatório realizado pela FGV-GVConsult (2004), sobre "O impacto Econômico dos 25 anos do McDonald's no Brasil", pode-se estabelecer a visão e a dimensão das relações existentes entre seus agentes:

"Restringindo a análise às atividades que se desenvolvem na cadeia de alimentos, ainda assim, ela revelará um grande número de atores, ações e negócios. Um Big-Mac vendido demanda diversos produtos manufaturados, ou seja, que passam por algum tipo de elaboração anterior. O pão foi produzido com algum tipo de farinha de trigo, que por sua vez é o produto do beneficiamento do trigo in natura, que por sua vez, é o resultado do plantio do trigo. Esse percurso reverso permite imaginar quantas relações estão envolvidas em todos os produtos produzidos na cadeia. Toda essa variedade envolve um grande número de etapas de produção, as quais seguem elos diferentes e, ao serem agrupadas, configuram uma mesma cadeia - a cadeia de alimentos (suprimentos), que começa na agropecuária, atravessa a indústria manufatureira e chega ao setor de serviços, na figura 
do PSL e dos restaurantes McDonald's". A figura 1 a seguir ilustra a estrutura típica da Cadeia de Suprimentos da Rede McDonald's.

Figura 1: Cadeia de Suprimentos da Rede McDonald's

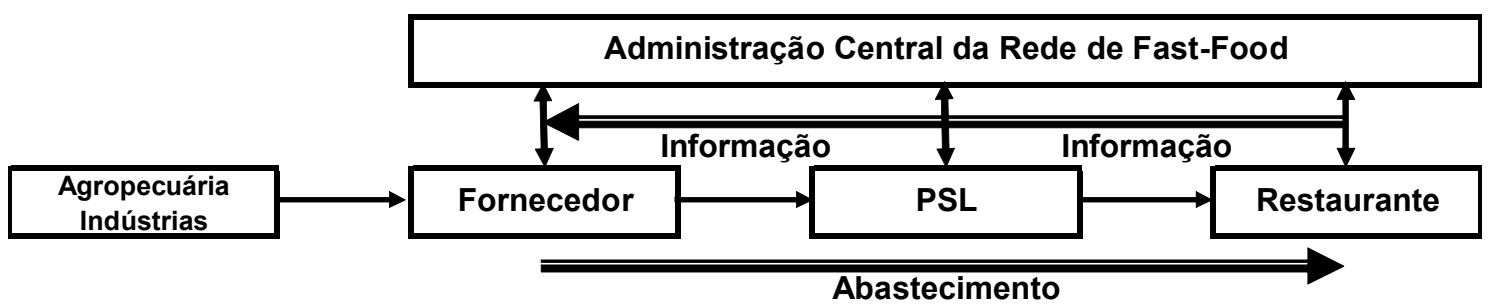

\subsection{Gestão da Cadeia}

Envolvidos no processo de abastecimento dos restaurantes, os fornecedores trabalham com o foco de não haver ruptura no fornecimento em momento algum. Ou seja, baseiam-se no fato de que o cardápio do restaurante deve ser atendido plenamente e o desejo de um item pelo consumidor não atendido reflete em perda direta da venda. Este conceito é forte e trabalhado com muita seriedade por todos os fornecedores.

O sistema de abastecimento dos restaurantes concentra-se no PSL (Prestador de Serviços Logísticos), que exerce importante papel no processo de integração das necessidades do McDonald's (restaurante e corporação) com os fornecedores. Controla a demanda dos pontos de venda, variáveis de venda ligadas à sazonalidade, recebe informações de promoção e informações da matriz, processa todos os dados e transforma em pedido aos fornecedores. Estes trabalham para atender aos pedidos, entregando-os aos centros de distribuição do PSL.

O PSL organiza e programa todo o processo de abastecimento dos pontos de venda. Orienta o pedido do restaurante, recebe a ordem, processa o faturamento, carrega o caminhão e abastece o ponto de venda na hora marcada. Parece um tanto quanto idealista ou perfeccionista, mas é isso mesmo que ocorre: o restaurante tem dia e hora para receber seus produtos e, com isso, pode manter e controlar o nível de estoque num patamar justo, pois pode confiar na entrega. Esta atinge 97\% de confiabilidade de horário (não atrasa mais de 30 minutos) com efetividade no acerto do pedido de $99,8 \%$, ou seja, quase não há falta de itens na entrega.

A corporação McDonald's, que é quem exerce a governança da cadeia, estabelece as responsabilidades com os agentes da cadeia, bem como negocia todas as variáveis relacionadas a preço, margens, qualidade e conflitos. Algumas vezes, quando uma empresa não atinge o alvo de lucro esperado na operação, discute-se meios para que ela consiga equilíbrio e se mantenha no sistema. Caso ocorra o inverso, por exemplo, um fornecedor consegue obter um resultado maior do 
que o negociado, o ressarcimento ao sistema tende a ocorrer, se não diretamente, mas em compensações no preço ou serviço.

O compromisso dos fornecedores e o grau de relacionamento estabelecido pelo McDonald's tem forte grau de cooperação e confiabilidade, a ponto de um grupo de fornecedores investirem independentemente num condomínio operacional dedicado ao Mcdonald's, o Food-Town, construído em Osasco - SP.

Percebe-se, em iniciativas como estas, que a gestão operacional da cadeia de suprimentos ganha profundas melhorias de performance, contribuindo com o sistema como um todo. Pode-se dizer, conforme afirma Chopra et al. (2001), que empresas na fronteira da eficiência estão continuamente melhorando seus processos e mudando tecnologias na busca de um novo nível de performance.

Nesta relação, o papel de cada agente participante da cadeia de suprimentos pode ser resumido em:

- Rede McDonald's (corporação): Operação dos restaurantes, estabelecimento de promoções e propagandas, seleção de fornecedores, preços e produtos, desenvolvimento de novos produtos, elaboração de planos estratégicos para o negócio, avaliação e padronização dos processos e resolução de conflitos na cadeia.

- PSL: Responsável pela gestão de compras e estoques, atendimento aos restaurantes, armazenagem, distribuição e transporte, transferências a outros centros de distribuição no País, gestão financeira da cadeia, planejamento logístico, planejamento físcal, serviço de campo e coordenação das operações de abastecimento na cadeia.

- Fornecedores: Manufatura com qualidade assegurada, desenvolvimento de novos produtos e gestão da cadeia de suprimentos a montante.

\section{Conclusão}

Ray Kroc, nos anos 50 e 60, iniciou o trabalho de construção dos princípios operacionais do McDonald's baseados em conceitos colaborativos, em que os envolvidos diretamente no fornecimento tinham apoio, incentivos e também compromissos com a melhoria dos produtos e do abastecimento, de forma que o resultado contribuísse para a expansão e melhoria do sistema. Estes princípios foram sendo fundamentos ao longo dos anos, e mesmo na expansão e implementação dos restaurantes em diversos países do mundo, seus gestores adotam o mesmo modelo de gestão. Desta forma, o fator cultural tem, no caso, forte importância para a gestão colaborativa, principalmente quando praticado pelo principal gestor da empresa. 
Por outro lado, atualmente o nome McDonald's é forte e tê-lo atrelado ao seu portifólio de clientes contribui com muitos novos negócios. Portanto, a relação pode ser baseada em compromissos mútuos. No entanto, para alguns fornecedores, a garantia de resultados favoráveis nos negócios com o McDonald's pode não ser uma realidade. É claro que esta situação não se aplica aos fornecedores exclusivos que só trabalham para o sistema. Apesar de serem empresas independentes, como são fundamentais para o sistema, sua sobrevivência precisa ser garantida.

O caso justifica a idéia de que quando não existe estrutura e embasamento na empresa foco sobre o processo colaborativo, o relacionamento baseado no interesse da cadeia não tem sustentação.

A expansão dos restaurantes McDonald's ocorrida ao longo dos anos demonstra que seu sistema colaborativo na cadeia de suprimentos é relativamente eficiente, considerando o sucesso da rede em diversos países, incluindo o Brasil.

Outro aspecto importante do estudo é a relevância das informações a respeito do sistema McDonald's, no sentido de se divulgar academicamente um modelo de gestão que atende muito bem o conceito de colaboração na cadeia de suprimentos.

As limitações do estudo são pertinentes à metodologia de estudo de caso, em que generalizações não podem ser feitas. Por outro lado, o caso estudado abre oportunidades para outras pesquisas, como a análise de outras empresas de sucesso que só adotaram os conceitos colaborativos da cadeia de suprimentos após anos de operação, demonstrando os mecanismos utilizados para superar as barreiras culturais e organizacionais do passado.

Também, este estudo não abordou questões relativas à performance ou vantagens competitivas que esse sistema de gestão permite, podendo, portanto, ser tema de outros estudos nesta área.

\begin{abstract}
Throughout the peer study of the supply chain of McDonald's, the research lays out how the collaborative relationship may be understood within the management system as well as in the supply process of restaurants. The theoretical groundwork explores the relationship in the supply chain management and the collaborative process as a means of coordination of the agents of the chain. As McDonald's is a representative case and of relative academic interest, chiefly within the supply management, it's also believed that the research may contribute to the understanding of the subject in question, other than making clear the factors which foster and benefit companies in the use of this very concept. Once regarding the discussion on collaborative relationship within the supply chain as a subject is still under development, this case helps to provide the basis to the ideas and upcoming studies toward the subject.
\end{abstract}

Key-words: Supply Chain; Collaborative Relationship. 


\section{Referências}

BARRATT, MARK. Positioning the Role of Collaborative Planning in Grocery Supply Chains. International Journal of Logistics Management. Vol.14 n.2, pg.53-66, 2003.

cross ${ }^{\text {ref }}$

BARRATT, MARK. Understanding the meaning of collaboration in the supply chain. Supply Chain Management: An International Journal, Vol. 9, n. 1, pg.30-42, 2004.

cross'

BARRATT, MARK. Unveiling Enablers and Inhibitors of Collaborative Planning. The International Journal of Logistics Management, Vol. 15, n.1, pg.73-90, 2004.

cross ${ }^{\text {ref }}$

BECKETT, RONALD C. Collaboration now a strategic necessity. Handbook of Bussiness Strategy, pp. 327-332, 2005.

BOWERSOX, DONALD J; Closs, David J; \& Stank, Theodore P. How to master cross-enterprise collaboration. Supply Chain Management Review, Jul/Aug 2003.

BRONZO, MARCELO. Relacionamentos Colaborativos em Redes de Suprimentos, Revista RAE, vol. 44, Edição Especial Minas Gerais, pg. 61-73, 2004.

CHRISTOPHER, MARTIN \& Towill, Denis. An integrated model for the design of agile supply chains, International Journal of Physical Distribution \& Logistics Management, Vol. 31, n. 4, pp.235-246, 2001.

cross ${ }^{\text {ref }}$

CHOPRA, S. \& Meindl, P. Supply chain management, New Jersey, Prentice Hall, pg. 23, 2001.

CLOSS, DAVID J.; Swink, Morgan; and Nair, Anand. The role of information connectivity in making flexible logistics programs successful, International Journal of Physical Distribution \& Logistics Management, Vol. 35, n.4, PP.258$277,2005$.

CORSTEN, DANIEL; and Feld, Jan. Exploring the Performance effects of Key-Supplier Collaboration. International Journal of Physical Distribution \& Logistics Management. Vol. 35, n. 6, pg. 445-461, 2005.

COOPER, MARTHA C.; Lambert, Douglas M.; and Pagh, Janus D. Supply Chain Management: More than a New Name for Logistics. The International Journal Of Logistics Management, Vol. 8, n.1, pg. 1-14, 1997.

cross ref

COX, ANDREW. The art of the possible: Relationship management in power regimes and supply chain. Supply Chain Management: An International Journal, Vol. 9, n. 5, pg.346-356, 2004.

cross ref

DORAN, DESMOND. Supply chain implications of modularization. International Journal of Operation \& Production Management. Vol.23, n.3, pp.316-326, 2003.

cross ref

HARRISON, ALAN, and Hoek, Van Remko. Logistics Management and Strategy. First edition, Financial Times/Prentice-Hall, London, 2002.

KOPCZAK, LAURA ROCK; \& Johnson, M. Eric. The Supply-Chain Management Effect. MIT Sloan Management Review, vol. 44 n. 03, pg. 27-34, 2003.

LOVE, JOHN F. McDonald's: a verdadeira história do sucesso, Rio de Janeiro: Editora Bertrand ,1996.

JOHANNESSEN, STIG, and Solem, Olav. Logistics Organizations: Ideologies, Principles and Practice, The International Journal of Logistics Management, vol.13 n. 1, Pg. 31-42, 2002.

cross'ef 
FGV-CONSULT, O Impacto Econômico dos 25 anos do McDonald's no Brasil, Fundação Getúlio Vargas (Estudo realizado pela FGV para o McDonald's - documento interno da empresa), 2004.

LAMBERT, DOUGLAS M.; Emmelhainz, Margaret A.; and Gardner, John T. Developing and Implementing Supply chain Partnerships. The International Journal of Logistics Management, vol. 7, n. 2, pg. 1-17, 1996.

LAMBERT, DOUGLAS M; and Burduroglu, Renan. Measuring and Selling the Value of Logistics, The International Journal of Logistics Management, vol. 11 n. 1, pg. 1-17, 2000.

cross ${ }^{\text {ref }}$

MIN, SOONHONG; Roath, Anthony S.; Daugherty, Patricia J.; Genchev, Stefan E.; Chen, Haozhe; and Arndt, Aaron D.; Supply Chain Collaboration: What's happening? The International Journal of Logistics Management, Vol. $16 \mathrm{n.}$ 2, pg. 237-256, 2005.

PECK, HELEN; and Juttner, Uta; Strategy and Relantionships: Defining the Interface in Supply Chain Contexts. International Journal of Logistics Management, vol. 11 n.2, pg. 33-44, 2000.

cross ${ }^{\text {ref }}$

RUNGTUSANATHAN, M.; Salvador F.; Forza C.; and Choi T.Y. Supply chain linkages and operational performance. International Journal of Operations \& Production Management; vol.23, n.9, pp. 1084-1099, 2003.

cross ref

SAHAY, B.S. Supply chain collaboration: The key to value creation. Work Study, Vol.52, n.1, pp.76-83, 2003.

cross ref

SIMATUPANG, TOGAR M, \& Sridharan, R. The Collaborative Supply Chain. International Journal of Logistics Management, Vol. 13, n. 1, pg. 15-30, 2002.

cross ref

SIMATUPANG, TOGAR M; Wright, Alan C.; \& Sridharan, R. The Knowledge of Coordination for Supply Chain Integration. Business Process Management Journal Bradford, vol. 8, n. 3, pg. 289-309, 2002.

cross ref

SIMATUPANG, TOGAR M; Wright, Alan C; \& Sridharan, R. Applying the Theory of Constraints to Supply Chain Collaboration. Supply Chain Management: An International Journal, Vol. 9 n.1, pg. 57-70, 2004.

cross ref

TEIXEIRA, FRANCISCO; \& Guerra, Oswaldo. Redes de Aprendizado em Sistemas Complexos de Produção. Revista R.A.E., Vol. 42 n.4, Pg. 93-105, 2002.

ZHAO, MENG \& Stank, Theodore P. Interactions between Operational and Relational Capabilities in Fast-food Service Delivery. Transportation Research part E, vol.39, pg. 161-173, 2003.

cross ref

Autores:

Mauro Vivaldini

Filiação institucional: Universidade Metodista de Piracicaba - UNIMEP

Departamento: Faculdade de Engenharia de Produção

Função ou cargo ocupado: Doutorando em Eng. De Produção

Endereço : Rua Pedro Cereser, 165 - Itupeva - SP - CEP 13925-000

Telefones para contato: 11-3687-2830// 11-4496-4614

e-mail: mvivaldini@mbbrasil.com.br

\section{Dr. Fernando Bernardi de Souza}


Filiação institucional: Universidade do Estado de São Paulo - UNESP

Departamento: Faculdade de Engenharia de Bauru - Eng. Produção

Função ou cargo ocupado: Professor

Endereço : Av. Eng. Edmundo Corrijo Coube, 14-01 - Bauru - SP - CEP 17033-360

Telefones para contato: 14-3103-6122 // 16-9127-3369

e-mail: fbernardi@feb.unesp.br

\section{Dr. Silvio R.I.Pires}

Filiação institucional: Universidade Metodista de Piracicaba - UNIMEP

Departamento: Faculdade de Engenharia de Produção

Função ou cargo ocupado: Professor

Endereço : Rod. Sta Barbara/Iracemópolis Km 1 - Sta Barbara - SP - CEP 13450-000

Telefones para contato: 19-3124-1805

e-mail:sripires@unimep.br

Recebido para publicação em: 23/04/07

Aceito para publicação em: 02/05/07 